\title{
Green Sustainable Island by Implementation of Environmental, Health, Safety and Energy Strategy in KISH Trading-Industrial Free Zones-IRAN
}

\author{
Amin Padash $^{1, *}$, M. Khodaparast ${ }^{2}$, A. Zahirian ${ }^{3}$, A. Kaabi Nejadian ${ }^{4}$ \\ ${ }^{1}$ Iranian Academic Center for Education, Culture \& Research - San'ati Sharif university branch, \\ Environmental Engineering Centre, Tehran- Iran \\ ${ }^{2}$ Contracts Department of National Iranian South Oil Fields Company, Ahwaz- Iran \\ ${ }^{3}$ Islamic Azad University Khuzestan Science \& Research Branch, Shiraz-Iran \\ ${ }^{4}$ Consultant of Director General of Renewable Energy Organization of Iran \\ *Corresponding author. Mob: +98912 3000 586, Fax: +98 21 88906044, E-mail: AminPadash@gmail.com
}

\begin{abstract}
The sustainable development of green islands for implement Environmental, Health and Safety Management Systems for free trade zones required to confirm to ISO 14001, OHSAS 18001 and ISO 50001 standards. The Standard development of policy and strategy for business and tourism requires, in first instance, a vision. It needs to trace down what are the main threats, where do they come from, and what can be done about it. The green economy has been growing globally at great pace over the past five years. This is all the more impressive considering the severe global downturn of years 2006-2009. Ireland has, in recent times, gained a presence in this exciting sector, with enterprise opportunities in a wide variety of areas.
\end{abstract}

Sustainable development considers Social, Economic, Energy and Environmental needs. Trading-Industrial Free Zones (TIFZ) purposes and duty must be met in sustainable ways. However, TIFZ have a good track record of finding sustainable solutions whilst balancing these purposes and duty.

The method used in this article is comparative and matching method, by using ISO 50001 standards which is approved by ISO, and HSE-MS which is structured by Oil and Gas Production (OGP). Jointing of Energy management by HSE-MS is the main objective of this paper.

This case study has attempted the Implementation of EHSE Strategy in Kish Islands which is in Persian Gulf of Iran. EHSE modeling will overarch strategic document and central to the future of the Kish. It shows coordination and integration with other plans, strategies and actions in the Kish where they affect the TIFZ purposes and duty. It indicates how the TIFZ purposes and associated duty will be delivered through sustainable development. Matching requirements of the environment with energy safety and health is the ultimate goal of this research. In fact, the clean environment, with safe and healthy quality and with optimum energy consumption pattern, is the most ideal strategy for the management of a green region. Surely this concept of sustainable Green Island will be achievable in the near future. According to the result of this research, successfully management system in the way of sustainable development, is to attached and used efficiency all of the parameters such as Environment, Safety, Health and Energy in the same way and with the total carrying capacity. Such sensitive development at Green Island will ensure that resort guests and day visitors will continue to enjoy a quality nature based experience within a magnificent rainforest and reef environment.

Keywords: Sustainable Islands-Environmental, Health, Safety and Energy Policy- KISH ISLAND

\section{Introduction}

The man is the main pivot in the sustainable development. Possibility, planning, and implementation of any project or plan which include even technical or economical advantage, if there were any disadvantages or if the principles of health, safety and environmental rules were in danger, it is not advisable to be recommended. Thus, the national and international standards are generated [4. Sustainable development is a pattern of resource use that aims to meet human needs while preserving the environment so that these needs can be met not only in the present, but also for future generations. The term was used by the Brundtland Commission which coined what has become the most often-quoted definition of sustainable development as development that "meets the needs of the present without compromising the ability of future generations to meet their own needs."[11][10] 
The field of sustainable development can be conceptually broken into three constituent parts: environmental sustainability, economic sustainability and sociopolitical sustainability. (fig.1) Requirements for health and safety and of environmental topics in the world are proof for anyone.In addition to, Energy has been playing an important role in the economic development all over the world. World population is expected to double by the middle of this century, and economic development will continue at a faster pace in the developing world than that in the developed world.[12]

Considering the matching of four mentioned subjects and their inevitable relations, in addition to their advantages of implementation, such as reducing the taxes and costs and being timesaver nowadays health, safety, environment and energy are studied and considered as a united group.If the system does not have an Environmental, Health, Safety \& Energy Management System (EHSE-MS) in place now, it may be required to implement one soon.[7] Free trade zones are domestically criticized for encouraging businesses to set up operations under the influence of other governments, and for giving foreign corporations more economic liberty than is given indigenous employers who face large and sometimes insurmountable "regulatory" hurdles in developing nations. However, many countries are increasingly allowing local entrepreneurs to locate inside FTZs in order to access export-based incentives. Because the multinational corporation is able to choose between a wide range of underdeveloped or depressed nations in setting up overseas factories, and most of these countries do not have limited governments, bidding wars (or 'races to the bottom') sometimes erupt between competing governments. Free Trade Zones are also known as Special Economic Zones in some countries. [5]

TIFZ look like live Company size, resource availability or markets served will not necessarily dictate when and if implementation will happen. And even though organization may have many of the components in place already for an easy transition to ISO 14001 or OHSAS 18001 or ISO 50001 (fig.2), the road to an effective EHSE-MS can be fast, furious and paved with various pitfalls.There are many reasons why organizations implement Environmental Health Safety \& Energy Management Systems that conform to ISO 14001 and/or OHSAS 18001 and ISO 50001 standards. Identifying occupational health and safety hazards and risks and the environmental impacts and also the procedure of usage the energy and also the energy efficiency of your company and employees is a given. However, more and more customers are demanding EHSE-MS as a requirement for doing business.

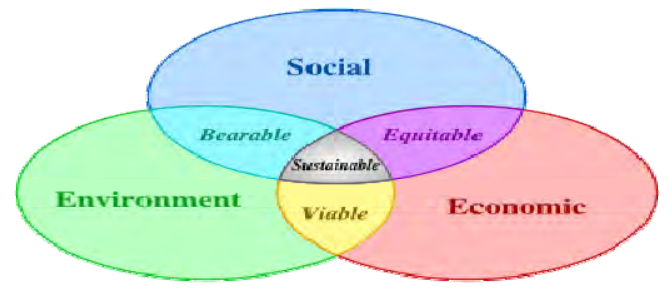

Fig.1- Scheme of sustainable development: at the confluence of three constituent parts.[4]

\subsection{Location (Kish Island)}

Kish is a resort island in the Persian Gulf. It is part of the Hormozgãn Province of Iran. Due to its free trade zone status it is touted as a consumer's paradise, with numerous malls, shopping centres, tourist attractions, and resort hotels. It has an estimated population of 20,000 residents and about 1 million people visit the island annually.[4] 
The area of the island is $91.5 \mathrm{~km}^{2}$. Kish Island is the purported to be the third most visited vacation destination city in the Middle East, after Sharm el-Sheikh and Dubai.

\subsection{Geography and Environment}

Kish is located in the Persian Gulf $19 \mathrm{~km}$ from mainland Iran and has an area of around $91 \mathrm{~km}^{2}$ with an outer boundary of $40 \mathrm{~km}$ and a nearly elliptical shape. Along Kish's coast are coral reefs and many other small islands. The Island is positioned along the $1359 \mathrm{~km}$ long Iranian coastline north of the Persian Gulf, at the first quarter from the Hormuz entrance to the Persian Gulf. Its longitudinal and latitudinal positions are 26.32N and 53.58E degrees. The Island is $15.45 \mathrm{~km}$ long from west coast to the east coast (the distance between Mariam Complex and Hoor field). (See Pic.1)[8]

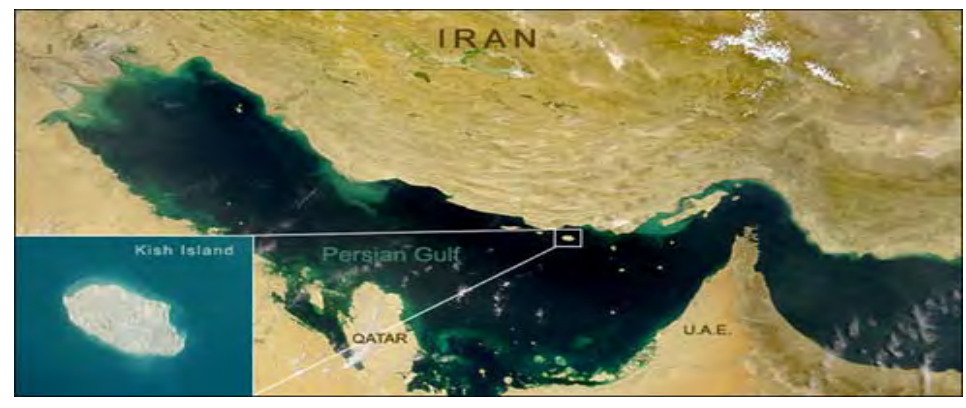

Picture1: Kish Island, Persian Gulf.

\subsubsection{Kish, a Scenery coral Reef}

The corals are considered as herbal and cylinder shaped animals which are mostly living as colony. Their Heads are located above cylinder in a way that a broad and wide screen exists in bottom part. These cells emit lime materials with the aim of fixing coral on a board. By emission of these materials, lime base will be created for coral. Aggregation and accumulation of corals and lime emissions from them, have played a very key role in various geological eras in appearance of Kish Island. Coral Islands and cylindrical forests enjoy the highest biodiversity in world ecosystems.[7][11]

\subsubsection{Kish Large Recreational Jetty}

Kish Large Recreational Jetty has been constructed by Iranian experts and engineers with the method of pipe driving and wooden deck with four- spacious satellite design. As long as 437 meters with 18 meters width and as large as 10,000 square meters, this jetty and quay has not any destructive effect on marine habitat in a way that tourists and sea voyagers can enjoy while standing on deck of this jetty and have a very pleasant time on visiting sceneries and breathtaking view of coral coasts of Kish Island.[9]

\subsection{Human impact-Major Kish Island Projects}

\subsubsection{International oil bourse}

The International Oil Bourse is a commodity exchange which opened on February 17, 2008.

\subsubsection{Dariush Grand Hotel}

Dariush, a \$125 million five star hotel with over 200 guest rooms, is located near the eastern sandy beaches of the island. The hotel was built to be a reminder of Persepolis, a symbol of the glory and splendor of the ancient Iranian civilization. The hotel was designed and 
developed by the European-Iranian entrepreneur and hotel tycoon, Hossein Sabet, who owns and manages several tourist attractions and hotels in the Canary Islands.[6]

\subsubsection{Kish Hidden Pearl}

In 1999, a project to build an underground complex was begun by 300 artists and excavation workers. After deep excavations rigid coral ceilings were discovered, and this was included in the final design. Once completed, the city will include restaurants, tourist resorts and underground therapeutic mud pools.

\subsubsection{Kish Dolphin Park}

The Dolphin Park is 10,000 square metres large and is surrounded by over 12,000 palm trees. The park includes a Dolphinarium, Butterfly Garden, Silkworm Compound, Exotic Bird Garden, Artificial Rain Forest, Volcanic Mountain, The World of Orchids and Cactus Garden.

\subsubsection{Solar Powered Hotel}

Hossein Sabet owner of the Sabet Hotels Group which includes the Dariush Grand Hotel and many other hotels on the island is set to build the first solar powered hotel in the Middle East on the island. Cyrus Hotel will be 7-star costing \$520 million and will have 500 rooms, 23 floors in an area of 100,000 square meters. The hotel is set to be complete in October 2009.[7][6]

\subsection{Extant Industries in Kish Island}

These industries are located in five industrial townships as follows:

$\checkmark$ Electricity and electronic industries

$\checkmark$ Home appliances industries

$\checkmark$ Metal and car manufacturing industries

$\checkmark$ Oil industry technical and engineering services and logistics industries

$\checkmark$ Garment and textile industries

$\checkmark$ Food, pharmaceutical and hygienic industries

$\checkmark$ Wooden and cellulose industries

$\checkmark$ Mineral and non-metallic industries

$\checkmark$ Chemical industries

$\checkmark$ Heating and cooling industries

$\checkmark$ Packing industries[12]

\section{Methodology}

The method used in this article is comparative and matching method, by using ISO 50001, ISO 14001, OHSAS 18001 and OGP for HSE-MS. All of these models are an international model, but the main goal is to match the requirement of energy management in Health, Safety and Environmental Management. Important in this research is how to use and the 4 components of sustainable development goals. [2][3][6][14]. Therefore, in order to implement this right and fundamental components relying on international standards on the one hand and the principles of sustainable development other hand, this model has been proposed.

\section{Results}

According to the investigations and analyzing the requirements of ISO 50001, ISO 14001, OHSAS 18001 and matching to the main HSE Standards, this result has been proposed. 
Following reviews carried out and matching of four main components environment, health, safety and energy, the proposed resulting model includes the following main axes: (Fig. 2)

1. Leadership and commitment

2. EHSE Policy and strategic objectives

3. Organization, resources and documentation

4. EHSE Risk Evaluation and management

5. Planning

6. Implementation and monitoring

7. EHSE Auditing and reviewing

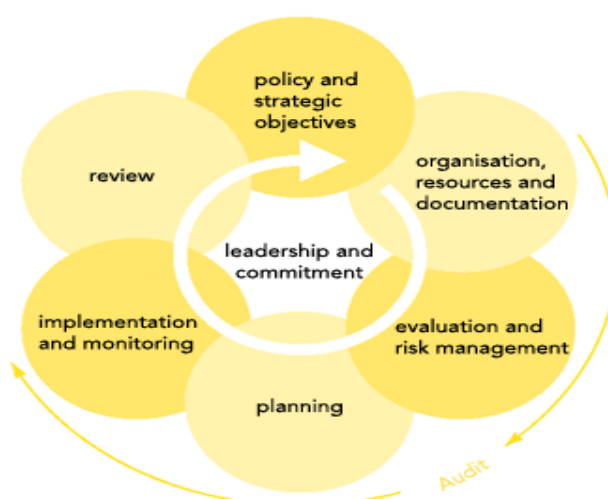

Fig.2- A proposed Model contain Environmental, Health, Safety and Energy part for Island.

\section{Discussion and Conclusion}

By definition EHSE, sustainable development will run by Health, and Safety (social), Energy (economic) and environmental needs. Kish Island purposes and duty must will be met in sustainable ways. However, Kish has a good track record of finding sustainable solutions whilst balancing these purposes and duty in EHSE ways.

To provide and describe the characterization of EHSE Strategy, the full description of every stage has been provided step by step:

\subsection{Leadership and commitment}

It addresses Top-down commitment and company culture, essential to the success of the system: The Kish Island (KI) Management should create and sustain an organization culture that supports the EHSMS, based on:

- Belief in the Kish Island's desire to improve EHSE performance;

- Motivation to improve personal EHSE performance;

- Acceptance of individual responsibility and accountability for EHSE performance;

- Participation and involvement at all levels in EHSEMS development;

- $\quad$ Commitment to an effective HSEMS.[10]

\subsection{EHSE Policy and strategic objectives}

It addresses corporate intentions, principles of action and aspirations with respect to environment, health \& safety. The Kish Island's management should define and document its EHSE policies and strategic objectives and ensure that they:

- $\quad$ are consistent with those of any parent company;

- $\quad$ are relevant to its activities, products and services, and their effects on EHS; 
- $\quad$ are consistent with the Kish Island's other policies;

- have equal importance with the Kish Island's other policies and objectives;

- are implemented and maintained at all organizational levels; are publicly available;

- commit the company to meet or exceed all relevant regulatory and legislative requirements; [9]

- apply responsible standards of its own where laws and regulations do not exist; commit the Kish Island to reduce the impacts, risks and hazards to health, safety and the environment of its activities, products and services to levels which are as low as reasonably practicable;

- Provide for the setting of EHSE objectives that commit the Kish Island to continuous efforts to improve EHSE performance.

\subsection{Organization, resources and documentation}

It addresses Organization of people, resources and documentation for sound EHSE performance.

The Kish Island should define, document and communicate-with the aid of organizational diagrams where appropriate - the roles, responsibilities, authorities, accountabilities and interrelations necessary to implement the EHSE MS, including but not limited to:

- provision of resources and personnel for EHSE MS development and implementation;

- initiation of action to ensure compliance with EHSE policy;

- acquisition, interpretation and provision of information on EHSE matters;

- recording of corrective actions and opportunities to improve EHSE performance;

- recommendation, initiation or provision of mechanisms for improvement, and verification of their implementation;

- control of activities whilst corrective actions are being implemented;

- control of emergency situations.

\subsection{EHSE Risk Evaluation and management}

Risk is present in all human endeavors. This section addresses the identification of EHSE hazards and evaluation of EHSE risks, for all activities, products and services, and development of measures to reduce these risks.

The essential steps of hazard management:

1. Identify hazards and effects

2. Establish screening criteria

3. Document significant hazards and effects and applicable statutory requirements

4. Evaluate hazards and effects

5. Implement selected risk reduction measures

6. Set detailed objectives and performances criteria

7. Identify and evaluate risk reduction measures

\subsection{Planning}

This section addresses the firm planning of work activities, including the risk reduction measures (selected through the evaluation and risk management process). This includes planning for existing operations, managing changes and developing emergency response measures. The Kish Island should maintain, within its overall work programmer, plans for achieving EHSE objectives and performance criteria. These plans should include:

- a clear description of the objectives; 
- designation of responsibility for setting and achieving objectives and performance criteria at each relevant function and level of the organization;

- the means by which they are to be achieved;

- resource requirements;

- time scales for implementation;

- motivating and encouraging personnel toward a suitable EHSE culture;

- mechanisms to provide feedback to personnel on EHSE performance;

- processes to recognize good personal and team EHSE performance

- mechanism for evaluation and follow-up.

\subsection{Implementation and monitoring}

This section addresses how activities are to be performed and monitored, and how corrective action is to be taken when necessary.

Activities and tasks should be conducted according to procedures and work instructions developed at the planning stage-or earlier, in accordance with EHSE policy:

- At senior management level, the development of strategic objectives

- and high-level planning activities should be conducted with due regard for the EHSE policy.

- At supervisory and management level, written directions regarding activities (which typically involve many tasks) will normally take the form of plans and procedures.

- At the work-site level, written directions regarding tasks will normally be

- in the form of work instructions, issued in accordance with defined safe systems of work (e.g. permits to work, simultaneous operations procedures, lock-off procedures, manuals of permitted operations).[10]

Management should ensure, and be responsible for, the conduct and verification of activities and tasks according to relevant procedures. This responsibility and commitment of management to the implementation of policies and plans includes, amongst other duties, ensuring that EHSE objectives are met and that performance criteria and control limits are not breached. Management should ensure the continuing adequacy of the EHSE performance of the Kish Island through monitoring activities. [10]

\subsection{EHSE Auditing and reviewing}

This section addresses the periodic assessment of system performance effectiveness and inherent suitability.[9]

The Kish Island should maintain procedures for audits to be carried out, as a normal part of business control, in order to determine:

- Whether or not EHSE management system elements and activities conform to planned arrangements, and are implemented effectively.

- The effective functioning of the EHSEMS in fulfilling the company's EHSE policy, objectives and performance criteria.

- Compliance with relevant legislative requirements.

- Identification of areas for improvement, leading to progressively better EHSE management.[10]

And at the end, as final conclusion, according to the proposed EHSE-MS model, it can improve environment, health, safety and energy performance resulting in pollution prevention, safer workplaces and fewer injuries in the islands. But even more than that, these 
systems are being used by organizations to gain a competitive edge. And as corporate social responsibility initiatives gain momentum, EHSE-MS takes on an even more critical role within the organization.

The main purpose of this model is to plan the EHSE model for other island such as Kish, to show the established overarching strategic document and central to the future of the TIFZ. It shows co-ordination and integration with other plans, strategies and actions in the TIFZ where they affect the TIFZ purposes and duty. It indicates how the TIFZ purposes and associated duty will be delivered through sustainable development by improve EHSE performance resulting. In addition to, this is the first research that shows the intergradations of this for main subject in one model in the world.

\section{References}

[1] Adams, Jeff (1993, 16 April). "Twinning Breaks Pledge, Says Expert". Calgary Herald. p. B11.

[2] American National Standard Institute, ISO 50001 on Energy Management Systems Approved as Draft International Standard, ANSI Publication, 2010

[3] C. A. Brebbia, Environmental Health Risk V, WIT Press, 2009, pp.142-148

[4] Committee on Environmental Policy. 2006. Environmental Performance reviews, Organization for Economic Co-operation and Development, United Nations Economic Commission for Europe. Published OECD online bookshop, Page: 166.

[5] Economics: Principles in action. Upper Saddle River, New Jersey 07458: Pearson Prentice Hall. 2003. pp. 454. ISBN 0-13-063085-3.

[6] International Association of Oil and Gas Producers, HSE management guidelines, OGP Publication, 1999, pp.15-24

[7] "Iran Travel And Tourism Forecast", Economist Intelligence Unit, August 18, 2008.

[8] Kish Free Zone Organization http://www.kish.ir/

[9] Millen, Joyce and Timoth Holtz, "Dying for Growth, Part I, The Politics of Globalization, ed. Mark Kesselman, Hougton Mifflin, 2007

[10] Padash, Amin, "Principles of Health, Safety and Environment Management System" Kavosh Ghalam pub. 2007. pp. 174. ISBN 964-2517-03-5

[11] Pearson School http://www.pearsonschool.com/index.cf

[12] Sargent, John and Matthews, Linda. "China vs. Mexico in the Global EPZ Industry: Maquiladoras, FDI Quality and Plant Mortality" (PDF)

[13] Smith, Charles; Rees, Gareth (1998). Economic Development, 2nd edition. Basingstoke: Macmillan. ISBN 0333722280.

[14] Suzan Linn Jackson, ISO 14001 implementation guide: creating an integrated management system, John Wiley and Sons, 1997, pp.34-45

[15] United Nations. 1987."Report of the World Commission on Environment and Development." General Assembly Resolution 42/187, 11 December 1987. Retrieved: 2007-04-12

[16] World Summit 2005 Outcome Document, World Health Organization, 15 September 2005 http://www.who.int/hiv/universalaccess2010/worldsummit.pdf 